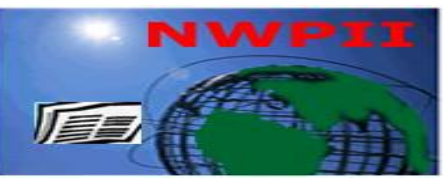

American Journal of Biomedical Sciences

ISSN: 1937-9080

nwpii.com/ajbms

\title{
Haemoglobin Genotype, ABO/Rhesus Blood Groups and Malaria among Students Presenting to a Private University Health Centre in Nigeria
}

\author{
Onaiwu T. OHIENGBOMWAN ${ }^{*}$, Priscilla ABECHI ${ }^{2}$, Testimony J. OLUMADE ${ }^{2}$ and \\ Nosakhare L. IDEMUDIA ${ }^{3}$
}

\author{
${ }^{1}$ Department of Health Services, Redeemer's University, Osun State, Nigeria. \\ "Corresponding Author \\ Onaiwu T. OHIENGBOMWAN \\ Department of Health Services, Redeemer's University,Osun State \\ Nigeria \\ Email: royalesteemplc@yahoo.com \\ Phone: +2348039143133
}

${ }^{2}$ African Centre of Excellence for Genomics of Infectious Diseases, Redeemer's University, Ede, Nigeria.

${ }^{3}$ Department of Medical Laboratory Services, University of Benin Teaching Hospital, Benin City, Nigeria.

Received:16 April 2019; | Revised:04 May 2019; | Accepted:05 December 2019

\begin{abstract}
Background: Malaria has remained a major issue of public health concern. Protozoan parasites of the genus Plasmodium are the causative agents of malaria and an infected Anopheles mosquito transmits the parasite. $\mathrm{Hb}$ genotype and $\mathrm{ABO}$ blood groups have been implicated as part of the host innate features that may confer protection against the infection. Methods: This study was a retrospective study which involved the use of laboratory data of students who reported for malaria test in 2017/2018 with the corresponding $\mathrm{Hb}$ genotype and $\mathrm{ABO} / \mathrm{Rh}$ esus blood groups identified. Results: A total of 2294 subjects participated in the study comprising 1039 (45.3\%) males and 1255 (54.7\%) females. From the study, 921 (40.1\%) subjects were malaria positive giving a prevalence of $40.1 \%$ among the participants. Blood group $\mathrm{O}(60.5 \%)$ had the highest distribution followed by group $\mathrm{B}(19.9 \%)$, A (17.5\%) and $\mathrm{AB}(2.1 \%)$. This same pattern of distribution was repeated for malaria positive and negative participants. The ABO/Rhesus blood group revealed the following pattern of distribution for malaria positive subjects: $\mathrm{ORh}+>\mathrm{BRh}+>\mathrm{ARh}+>\mathrm{ORh}->$ ARh- $>$ ABRh- $>$ BRh- $>$ ABRh $+\{58.3 \%, 17.9 \%, 16.5 \%, 2.8 \%, 2.1 \%, 0.9 \%, 0.8 \%$ and $0.8 \%\}$ and $\mathrm{ORh}+>$ $\mathrm{BRh}+>\mathrm{ARh}+>\mathrm{ORh}->\mathrm{ABRh}+>\mathrm{ARh}->\mathrm{BRh}->\mathrm{ABRh}-\{56.7 \%, 20.5 \%, 16.2 \%, 3.4 \%, 2.1 \%, 0.7 \%, 0.3 \%$ and $0.2 \%$ for malaria negative subjects. Meanwhile, 2127 (94.7\%) were Rhesus positive while $122(5.3 \%)$ were Rhesus negative, out of the 921 malaria positive subjects, 861 (93.5\%) were Rhesus positive while 60 $(6.5 \%)$ were Rhesus negative. HbAA $(66.7 \%)$ had the highest distribution among the study participants followed by $\mathrm{HbAS}(23.8 \%)$, HbSS (4.8\%), HbAC (2.9\%), HbSC (1.8\%) and HbCC (0.04\%), this was the same pattern observed among malaria positive and negative subjects. Conclusion: The high prevalence of malaria in this study is a pointer to the high level of endemicity and asymptomatic nature of malaria in this part of the world.
\end{abstract}




\section{Introduction}

Malaria has remained a major issue of public health concern. The World Health Organization reports that 97 countries and territories are endemic for malaria with an estimated population of 3.2 billion people at risk and 216 million cases every year leading to 445,000 deaths ${ }^{[1]}$. Nigeria has reported approximately 51 million cases and 207,000 deaths annually, accounting for the world's greatest malaria burden ${ }^{[2]}$.

Protozoan parasites of the genus Plasmodium are the causative agents of malaria and an infected Anopheles female mosquito transmits the parasite ${ }^{[3,4]}$. In individuals who show resistance to malaria, a variety of host innate features that may confer protection against the infection, in addition to host immunity, have been implicated [5,6]. The haemoglobin genotype and $\mathrm{ABO}$ blood grouping constitute a few of such features and there is growing evidence, both epidemiological and molecular, that report a relationship between these innate features and the relative risk of infection with Plasmodium falciparum ${ }^{[7,8]}$.

The human haemoglobin $(\mathrm{Hb})$ is formed from two pairs of globin chains with a molecule of haem attached. The major types of haemoglobin molecules include foetal and adult haemoglobins. The foetal haemoglobin $(\mathrm{HbF})$ is found in the foetus while the adult haemoglobin as found in adults can be classified into $\mathrm{HbA}, \mathrm{HbC}$ and $\mathrm{HbS}$ which is encountered in the sickle disease ${ }^{[7]}$. The inheritance of any of the haemoglobin gene from both parents can lead to any of these combinations: HbAA, $\mathrm{HbSS}, \mathrm{HbCC}, \mathrm{HbAS}, \mathrm{HbAC}, \operatorname{HbSC}{ }^{[9,10]}$.

The ABO blood group system is very important in medicine. Blood transfusion became safer after Karl Landsteiner, an Austrian Biologist, discovered the ABO blood grouping in $1901^{[7]}$. All humans belong to at least one of the blood groups: $\mathrm{A}, \mathrm{B}, \mathrm{AB}$ and $\mathrm{O}$. The $\mathrm{ABO}$ blood group system consists of carbohydrate antigens $\mathrm{A}, \mathrm{B}$ and $\mathrm{H}$, which has the capacity to regulate the activities of proteins during infections and against these antigens. These antigens are formed by the terminal glycosylation of glycoproteins and glycolipid chains present on cell surfaces ${ }^{[5,11]}$.

The parasite has developed several ways of evading the host immune system while in the erythrocytic stage of its life cycle. Rosetting, the binding of infected red blood cells (RBCs) to uninfected RBCs, is a virulence phenomenon that Plasmodium falciparum employs in order to cause infection, and it has been shown to cause severe malaria in African children [12]. Furthermore, rosetting has also been suggested to be a mechanism through which the parasite facilitates transmission of merozoites from infected RBCs into uninfected RBCs by means of 'direct passage', although, the confirmation of this hypothesis in vitro is yet to be ascertained. A few studies have revealed that rosetting parasites do not multiply better than nonrosetting clones in vitro ${ }^{[12,13]}$.

Studies have revealed that rosetting is reduced in individuals with blood group O. Although, the rosetting capacities of blood groups $\mathrm{A}, \mathrm{B}$ and $\mathrm{AB}$ are still being debated, there are studies showing that rosetting is more prominent in individuals with blood group A ${ }^{[13,14]}$. According to a case-control study carried out by one researcher ${ }^{[15]}$, the blood group $\mathrm{O}$ confers protection on its host against severe malaria through reduced rosetting. Although, the molecular basis for this is yet to be completely understood, studies have reported that a sub-group of Plasmodium falciparum erythrocyte membrane protein 1 (pfEMP1) adhesins, encoded by a large var gene family, are responsible for rosetting ${ }^{[14,16]}$.

Variations in another gene which encodes an enzyme, Glucotransferase, have also been reported to be associated with protection against severe $P$. falciparum malaria. This is because Glucotransferase is responsible for the production of $A$ and $B$ antigens present on the surface of RBCs in individuals with blood groups $\mathrm{A}, \mathrm{B}$ and $\mathrm{AB}$. The $\mathrm{A}$ and $\mathrm{B}$ antigens are trisaccharides consisting of GalNAca1-3(Fuca1-2)Gal1b1 and BGal1a13(Fuca1-2)Galb1 respectively with different glycoproteins and glycolipids attached, while the blood group ' $\mathrm{O}$ ' carries a disaccharide $\mathrm{H}$ antigen (Fuca1-2Galb1) due to the absence of the enzyme. These trisaccharides of antigens A and B have been proposed to act as receptors in rosette formation, 
thus, rosettes formed by RBCs in individuals with blood group $\mathrm{O}$ are smaller and easily disrupted when compared with those formed by 'A', 'B' or 'AB' blood groups. Rosette formation and sequestration impair blood flow leading to tissue ischemia and death ${ }^{[15,17]}$.

Studies have also revealed that the haemoglobin variants also influence the distribution and transmission of Plasmodium falciparum malaria in humans ${ }^{[6]}$. Two haemoglobinopathies-HbS and $\mathrm{HbC}$ (with genotypes AS and AC respectively) have been reported to protect against severe malaria compared with their HbAA counterparts but the influence of these two haemoglobinopathies on other parameters that are not directly linked to malaria severity varies. Different hypotheses have been proposed to explain the protection conferred by haemoglobin genotypes $\mathrm{AS}$ and $\mathrm{AC}$ against malaria. They include, but not limited to, impaired development of the parasite at the blood stage, reduced cytoadherence of infected RBCs and enhanced acquisition of immunity ${ }^{[6,18,19]}$.

Furthermore, protein targets of specific antibodies may be more exposed on the surface of $\mathrm{RBCs}$ with $\mathrm{Hb} \mathrm{S}$ or $\mathrm{C}$ resulting in enhanced immunity. However, concerning other parameters such as gametocyte carriage and infection chronicity, they differ. HbS has been associated with reduced gametocyte carriage while $\mathrm{HbC}$ has been associated with frequent gametocyte carriage ${ }^{[6 \text {, }}$ 20].

Due to the nature of the malaria burden in Nigeria and with $97 \%$ of the population being at risk of infection ${ }^{[2]}$, quite a few studies have been carried out to evaluate the role that haemoglobin genotypes and $\mathrm{ABO} /$ Rhesus blood groups play on the distribution of $P$. falciparum malaria among the populace. This study was designed to evaluate the distribution/relationship of haemoglobin genotypes and $\mathrm{ABO} /$ Rhesus blood groups among students population of a private university in Nigeria presenting for malaria test.

\section{Materials and Methods}

This study was a retrospective study conducted at Redeemer's University Health Centre. Laboratory database of students who reported for malaria test in 2017/2018 was assessed and the corresponding haemoglobin genotype and $\mathrm{ABO} /$ Rhesus blood groups identified. Approval for the study was given by the Institutional Research Ethics Committee (RUN-IREC: 009). Patient confidentiality was guaranteed during this study as only laboratory authorized personnel were granted access into the database and the data generated were de-identified before it was released to the researchers.

Within the period under review, blood group was done using tile agglutination method with antisera from Lorne Laboratories, UK. while the haemoglobin genotype was carried out using consort EV 245 electrophoresis machine from Helena Laboratories, Texas. The malaria test was carried out with the use of rapid diagnostic test kits (global malaria $\mathrm{pf} / \mathrm{pv}$ rapid test kit, USA) and microscopy methods.

\section{Results}

A total of 2294 participants were included in the study comprising 1039 (45.3\%) males and 1255 $(54.7 \%)$ females (table 1). From the study, 921 $(40.1 \%)$ subjects were malaria positive giving a prevalence of $40.1 \%$ among the study subjects. Participants with blood group $\mathrm{O}(60.5 \%)$ had the highest distribution among the study subjects followed by blood group B (19.9\%), A (17.5\%) and $\mathrm{AB}(2.1 \%)$. This same pattern of $\mathrm{ABO}$ blood group distribution was repeated for malaria positive and negative participants as shown in table 3 . 
Table 1: Gender distribution of study subjects

$\frac{\text { MALE }}{\text { MP+ MP- TOTAL(\%) }} \begin{gathered}\text { FEMALE } \\ \text { MP+ MP- TOTAL(\%) }\end{gathered}$ TOTAL

\begin{tabular}{|c|c|c|c|c|c|c|c|}
\hline $\mathbf{O}$ & 293 & 323 & $616(44.4)$ & 270 & 502 & $772(55.6)$ & 1388 \\
\hline B & 94 & 124 & $218(47.7)$ & 78 & 161 & $239(52.3)$ & 457 \\
\hline $\mathbf{A}$ & 101 & 99 & $200(49.8)$ & 70 & 132 & $202(50.2)$ & 402 \\
\hline $\mathrm{AB}$ & 03 & 02 & 05 (10.6) & 12 & 30 & $42(89.4)$ & 47 \\
\hline $\begin{array}{l}\text { TOTAL } \\
\text { HbGT }\end{array}$ & 491 & 548 & $1039(45.3)$ & 430 & 825 & $1255(54.7)$ & 2294 \\
\hline $\mathbf{A A}$ & 359 & 329 & 688 (44.9) & 293 & 550 & $843(55.1)$ & 1531 \\
\hline AS & 97 & 132 & $229(41.9)$ & 102 & 215 & $317(58.1)$ & 546 \\
\hline SS & 18 & 58 & $76(69.7)$ & 13 & 20 & $33(30.3)$ & 109 \\
\hline $\mathbf{A C}$ & 11 & 16 & $27(40.9)$ & 14 & 25 & $39(59.1)$ & 66 \\
\hline SC & 06 & 12 & $18(43.9)$ & 08 & 15 & $23(56.1)$ & 41 \\
\hline $\mathrm{CC}$ & 0 & 01 & $01(100)$ & 0 & 0 & 0 & 01 \\
\hline TOTAL & 491 & 548 & $1039(45.3)$ & 430 & 825 & $1255(54.7)$ & 2294 \\
\hline
\end{tabular}

KEY: BG-Blood group MP+ malaria parasite positive MP- malaria parasite negative HbGT- Haemoglobin Genotype

The general pattern of ABO blood group distribution between male and female gender remained unchanged. However, there was a slight change in the pattern among malaria positive male participants, where blood group A $(20.6 \%)$ was higher than Blood group B (19.1\%) which however did not affect the overall distribution.

The $\mathrm{ABO} /$ Rhesus blood group distribution in this current study (table 2) revealed the following pattern of distribution for malaria positive subjects:
$\mathrm{ORh}+>\mathrm{BRh}+>\mathrm{ARh}+>\mathrm{ORh}->\mathrm{ARh}->\mathrm{ABRh}->$ $\mathrm{BRh}->\mathrm{ABRh}+$ with the following distribution $58.3 \%, 17.9 \%, 16.5 \%, 2.8 \%, 2.1 \%, 0.9 \%, 0.8 \%$ and $0.8 \%$ respectively. Meanwhile, for malaria negative participants, the following pattern was observed: $\mathrm{ORh}+>\mathrm{BRh}+>\mathrm{ARh}+>\mathrm{ORh}->\mathrm{ABRh}+>\mathrm{ARh}->$ BRh- $>$ ABRh- with the following distribution (56.7\%, 20.5\%, 16.2\%, 3.4\%, 2.1\%, 0.7\%, 0.3\% and $0.2 \%$ ) respectively.

Table 2: Distribution of ABO/Rhesus blood group among study subjects

\begin{tabular}{|c|c|c|c|c|c|c|c|}
\hline \multirow[b]{2}{*}{ BG } & \multicolumn{3}{|c|}{ MP+ } & \multicolumn{3}{|c|}{ MP- } & \multirow{2}{*}{$\begin{array}{c}\text { COMBINED } \\
\text { TOTAL }(\%)\end{array}$} \\
\hline & Rh+ & Rh- & TOTAL & $\mathbf{R h}+$ & Rh- & $\overline{\text { TOTAL }}$ & \\
\hline $\mathbf{O}$ & 537 & 26 & 563 & 779 & 46 & 825 & $1388(60.5)$ \\
\hline B & 165 & 07 & 172 & 281 & 04 & 285 & 457 (19.9) \\
\hline $\mathbf{A}$ & 152 & 19 & 171 & 222 & 09 & 231 & $402(17.5)$ \\
\hline $\mathrm{AB}$ & 07 & 08 & 15 & 29 & 03 & 32 & $47(2.1)$ \\
\hline TL & 861 & 60 & 921 & 1311 & 62 & 1373 & $2294(100)$ \\
\hline
\end{tabular}

KEY: BG-Blood group MP+ malaria parasite positive MP- malaria parasite negative , $\mathrm{Rh}+\mathrm{Rhesus}$ positive, $\mathrm{R} h-$ Rhesus negative, TL- Total

For the Rhesus blood group of participants, $2127(94.7 \%)$ were Rhesus positive while 122 $(5.3 \%)$ were Rhesus negative, out of the 921 malaria positive subjects, $861(93.5 \%)$ were Rhesus positive whereas $60(6.5 \%)$ were Rhesus negative as in table 3. 
Table 3: Distribution of Haemoglobin genotype, ABO and Rhesus blood groups among study subjects

\begin{tabular}{llll}
\hline & MP+ (\%) & MP- $(\%)$ & TOTAL $(\%)$ \\
\hline HbGT & & & \\
AA & 652 & 879 & $1531(66.7)$ \\
AS & 199 & 347 & $546(23.8)$ \\
SS & 31 & 78 & $109(4.8)$ \\
AC & 25 & 41 & $66(2.9)$ \\
SC & 14 & 27 & $41(1.8)$ \\
CC & 0 & 01 & $01(0.04)$ \\
TOTAL & $\mathbf{9 2 1}(\mathbf{4 0 . 1 )}$ & $\mathbf{1 3 7 3}(\mathbf{5 9 . 9 )}$ & $\mathbf{2 2 9 4 ( 1 0 0 )}$ \\
ABO BG & & & \\
O & 563 & 825 & $1388(60.5)$ \\
B & 172 & 285 & $457(19.9)$ \\
A & 171 & 231 & $402(17.5)$ \\
AB & 15 & 32 & $47(2.1)$ \\
TOTAL & $\mathbf{9 2 1}$ & $\mathbf{1 3 7 3}$ & $\mathbf{2 2 9 4}(\mathbf{1 0 0})$ \\
Rh BG & & & \\
Rh+ & 861 & 1311 & $2172(94.7)$ \\
Rh- & 60 & 62 & $122(5.3)$ \\
TOTAL & $\mathbf{9 2 1 ( 4 0 . 1 )}$ & $\mathbf{1 3 7 3 ( 5 9 . 9 )}$ & $\mathbf{2 2 9 4}(\mathbf{1 0 0})$ \\
& & & \\
\hline
\end{tabular}

KEY: BG-Blood group MP+ malaria parasite positive $\mathrm{MP}-$ malaria parasite negative , $\mathrm{Rh}+\mathrm{Rhesus}$ positive, $\mathrm{Rh}-$ Rhesus negative, HbGT- Haemoglobin genotype

In the genotype distribution of the study subjects, as shown in table 3, HbAA (66.7\%) had the highest distribution among the study participants followed by $\mathrm{HbAS}(23.8 \%)$, $\mathrm{HbSS}(4.8 \%)$, $\mathrm{HbAC}$ $(2.9 \%)$, HbSC $(1.8 \%)$ and $\mathrm{HbCC}(0.04 \%)$. The pattern of distribution remained the same among malaria positive and negative subjects. Meanwhile, in the genotype distribution of female participants (table 1), HbAC (3.1\%) had a higher distribution than $\operatorname{HbSS}(2.6 \%)$ as against the general pattern of distribution observed in this study (table 3 ).

\section{Discussion}

The $40.1 \%$ prevalence of malaria recorded in this study, although higher than some other reports from both the same and other geographical regions of the country ${ }^{[21,22]}$, buttresses the fact that malaria is endemic in Nigeria where it accounts for more cases and deaths than any other country in the world. This is also a reflection of the high rate of asymptomatic plasmodium parasitaemia in endemic regions ${ }^{[23]}$ such as Nigeria. However, this could also be due to the geographical location of the study site which is largely suburban.

Determination of the various $\mathrm{ABO} / \mathrm{Rh}$ blood group distributions and their association with malaria infection has paramount significance in the context of transfusion medicine and malaria control ${ }^{[23]}$. In this study, a high prevalence of the blood group $\mathrm{O}$ phenotype $(60.5 \%)$ was observed among study participants followed by B (19.9\%), A (17.5\%) and $\mathrm{AB}(2.1 \%)$. These results are consistent with the reports from a research conducted in Northeastern Nigeria ${ }^{[24]}$. It is known that people with blood type $\mathrm{O}$ are protected from dying of severe malaria, and that blood group $\mathrm{O}$ confers protection against severe Plasmodium falciparum malaria through reduced rosetting $[15,25]$. This may explain why blood type $\mathrm{O}$ seems to be the most prevalent blood type in malaria endemic countries and in this current study. The $\mathrm{ABO}$ blood group frequencies recorded in this study: $O>B>A>A B$, agreed with some other studies that reported high group $\mathrm{O}$ frequency in malaria endemic regions as compared to other blood groups ${ }^{[7,10,26,39]}$.

Conversely, it has been reported that malariafree cold regions harbour higher frequency of blood 
group A phenotype than $\mathrm{O}{ }^{[23,27]}$. Although, one researcher [28] reported a different distribution pattern of a high frequency of blood group $\mathrm{O}$ followed by blood group A. It may be safe to mention that this distribution of blood groups is not exclusive and is geographically and ethnically dependent ${ }^{[5]}$. This claim is further strengthened by the observation of a totally different pattern from studies conducted in malarious areas of India where one researcher ${ }^{[29]}$ observed the B phenotype as the most abundant blood group in the region. This current report agrees with a study conducted on the Gwari tribe of Abuja and the Rubuka tribe of Plateau state, both in Nigeria ${ }^{[30]}$.

In addition to this, as regards the Rhesus factor, $94.7 \%$ of the population in this study was $\mathrm{Rh}+$, while the remaining $5.3 \%$ was Rh-. The prevalence of Rh-, even when minimal, is not insignificant considering its medical implications in pregnancy and child birth, arising from haemolytic disease of the newborn ${ }^{[31]}$.

The $66.7 \%$ prevalence of the haemoglobin AA genotype recorded in this study is in agreement with the figure reported for blacks $(55-75 \%)$ while the $23.8 \%$ prevalence of the AS genotype also agrees with the figure reported for Nigerians (20-30\%) and for Africa in general (20-40\%) ${ }^{[32]}$. The $4.8 \%$ prevalence of $\mathrm{HbSS}$ also agrees with the reported figure for Africans in general (1-10\%). Although a population study in North-west Nigeria, Southsouth Nigeria and Kenya recorded a zero percent prevalence of the HbSS genotype, this could infer a varying inherited haemoglobin variants amongst populations around the world ${ }^{[30,33]}$.

We observed malaria parasitaemia significantly more common in subjects with genotype AA than in those with the other haemoglobin genotypes. Individuals with haemoglobin genotype AA are very susceptible to malaria infection because the red cells are conducive for the growth and development of the parasite ${ }^{[34]}$. From results obtained in this study and reports of previous and similar studies, it is also clear that malaria infection rates were lowest for $\mathrm{HbSS}$ followed by HbAS. This is consistent with the reports of some earlier studies, which stated that the allele that causes sickle cell anaemia, $\mathrm{Hb} \mathrm{S}$, imparts resistance to malaria infection, as it is known to interfere with the growth and reproduction of malaria parasites. This has been recorded to occur through a reduction in the intake or release of oxygen due to the sickle nature of the red cell, and this results in the removal of sickle red cells from circulation before the malaria parasites are able to complete their life cycle ${ }^{[8,34,35]}$.

It should also be stated that patients who are heterozygous for the sickle trait gene (HbAS, HbAC) are usually more resistant to Plasmodium falciparum infection than those who are homozygous (HbSS, HbAA) ${ }^{[8]}$. Several mechanisms such as the impaired entry into and growth of the malaria parasites have been suggested to explain this protective effect. As such, the nonuniform trend in the prevalence rate of malaria among individuals in the same blood group and Rhesus factor could be due to other factors. These factors include demography, the Plasmodium species causing the infection, age, medical status, gender and other genetic factors such as variation in structure and chemical composition of the receptor sites on the erythrocytic membrane of various groups, which are known to play an important role in determining susceptibility to malaria infection ${ }^{[8}$ 36].

In one study ${ }^{[37]}$ carried out in a Teaching Hospital in Ekiti state, Nigeria, individuals with haemoglobin genotype $\mathrm{AS}$ and $\mathrm{AC}$ suffer lower incidences and less severe malaria compared to HbAA. Another study ${ }^{[38]}$, observed that the ability to control haem effectively during acute infection led to a milder proinflammatory response in individuals with $\mathrm{Hb}$ AS and AC. This may explain the reduced susceptibility to the severe disease as high levels of proinflammatory cytokines have been reported to cause dyserythropoiesis, which can result in severe malarial anaemia. A similar study [24], conducted among under-five nomadic Fulani in North-eastern part of Nigeria observed that, as regards haemoglobin genotypes, infection was higher in HbAA individuals than in other genotypes while HbSS individuals were not infected at all. They also observed that individuals with blood group A were the most infected followed by blood group B and the least infected was blood group $\mathrm{O}$.

Conversely, one study ${ }^{[22]}$ carried out in Bauchi state, Nigeria, did not observe any significant differences in malaria prevalence in relation with the ABO blood groups. Interestingly, another study 
carried out in Delta state [39] supported this observation and also did not observe any significant association between the ABO blood types and malaria parasitaemia. They concluded that all ABO blood groups are equally at risk of the infection. More interestingly, a similar study conducted in Ogbomoso, Nigeria [35], observed the highest malaria prevalence in individuals with haemoglobin genotype SS and SC, followed by those with AS and $\mathrm{AC}$ while the least prevalence was observed in genotype AA individuals. They also observed higher malaria prevalence in blood group $\mathrm{O}$ individuals than in other blood groups.

Based on gender differences, there are mixed rates of infection when both genders are considered according to their genotypes. This was determined by the ratio of malaria positive males with the genotype to the total number of malaria positive individuals for that gender. In this study, the male and female population of HbAA genotype infection rates were $(73.12 \%)$ and $(68.14 \%)$ respectively. Genotype AS male and female malaria infection rates were $19.76 \%$ and $23.72 \%$, while $3.67 \%$ and $3.02 \%$ for $\mathrm{HbSS}, 2.24 \%$ and $3.26 \%$ for $\mathrm{HbAC}$, $0.20 \%$ and $1.86 \%$ for HbSC genotypes, and $0 \%$ for $\mathrm{HbCC}$ as shown in Table 1.

\section{Conclusion}

The high prevalence of malaria in this study is a pointer to the high level of endemicity and asymptomatic nature of malaria in this part of the world. As a result, malaria control should be a concerted effort of all stake holders including the governments at all levels and donor agencies while allowing the people themselves to undertake key roles in the control of the menace. Furthermore, we like to recommend that all blood donors/blood for transfusion be screened for malaria before given to the recipients.

\section{Acknowledgement}

The authors wish to appreciate the support of the management of Redeemer's University Health Centre and the laboratory staff for their technical support.

\section{References}

1 World Health Organization .World malaria report;WHO Press:Geneva, Switzerland, 2017; pp 1-199.

2 Dawaki S, Al-Mekhlafi HM, Ithoi I, Ibrahim J, Atroosh WM, Abdulsalam AM, Sady H, Elyana FN, Adamu AU, Yelwa SI, Ahmed A, Al-Areeqi MA, Subramaniam LR, Nasr NA, Lau YL. Is Nigeria winning the battle against malaria? Prevalence, risk factors and KAP assessment among Hausa communities in Kano State. Malar J 2016; 15: 351 DOI: 10.1186/s12936-016-1394-3

3 Hussain, A.;Ahmad, T.; Jamal, S.G.; Inamullah. Prevalence of Human Malaria Infection in Lal Qilla Pakistan,American Journal of Biomedical Sciences, 2015, 7(1), 9-14. DOI: 10.5099/aj150100009

4 Zakovic S, Levashina EA. NF-kappaB-Like Signaling Pathway REL2 in Immune Defenses of the Malaria Vector Anopheles gambiae. Front Cell Infect Microbiol 2017; 7: 258 DOI: 10.3389/fcimb.2017.00258

5 Bamou, R.; Sevidzem, S.L. ABO/Rhesus blood group systems and malaria prevalence among students of the University of Dschang, Cameroon, Malaria World Journal, 7(4), 1-4.

6 Goncalves BP, Sagara I, Coulibaly M, Wu Y, Assadou MH, Guindo A, Ellis RD, Diakite M, Gabriel E, Prevots DR, Doumbo OK, Duffy PE. Hemoglobin variants shape the distribution of malaria parasites in human populations and their transmission potential. Sci Rep 2017; 7(1): 14267 DOI: $10.1038 / \mathrm{s} 41598-017-14627-y$

7 Sani, M. The study of ABO blood groups and haemoglobin genotypes in Hassan Usman Katsina Polytechnic, Katsina, Nigeria, International Journal of Research Studies in Biosciences, 2014, 12(1), 198-200.

8 Amala,S.E.;Nwibani, C.P.Malaria in pregnancy and its association with ABO blood group and Haemoglobin Genotype, International Journal of Developmental Research, 2015, 5(8), 5317-5320. DOI: $\underline{10.1016 / \mathrm{S} 0140-}$ 6736(04)17446-1

9 Medugu, J.T.; Abjah, U.; Nasir, I.A.; Adegoke, S.; Asuquo, E.E. Distribution of ABO, Rh D blood groups and hemoglobin phenotypes 
among pregnant women attending a Tertiary Hospital in Yola, Nigeria, Journal of Medicine in the Tropics, 2016, 18(1), 38- 42. DOI: 10.4103/2276-7096.177829

10 Ohiengbomwan, O.T;Idemudia, N.L.;Owoicho, O.; Adeyanju, A.A. Gene Frequencies of Haemoglobin Genotype, ABO and Rhesus Blood Groups among Students Population of a Private University in Nigeria-Implications for Blood Banking, International Journal of Life Sciences and Scientific Research, 2018, 4(4), 1851-1857. DOI: 10.21276/ijlssr.2018.4.4.1

11 Kuadzi, J.T.; Ankra-Badu, G.; Addae, M.M. Plasmodium falciparum malaria in children at a tertiary teaching hospital: ABO blood group is a risk factor, The Pan African Medical Journal, 2011, 10, 2.

DOI: $10.11604 /$ pamj.2011.10.2.84

12 Ribacke U, Moll K, Albrecht L, Ahmed Ismail H, Normark J, Flaberg E, Szekely L, Hultenby $\mathrm{K}$, Persson KE, Egwang TG, Wahlgren M. Improved in vitro culture of Plasmodium falciparum permits establishment of clinical isolates with preserved multiplication, invasion and rosetting phenotypes. PLoS One 2013; 8(7):e69781

DOI: $10.1371 /$ journal.pone.0069781

13 Moll K, Palmkvist M, Ch'ng J, Kiwuwa MS, Wahlgren M. Evasion of Immunity to Plasmodium falciparum: Rosettes of Blood Group A Impair Recognition of PfEMP1. PLoS One 2015; 10(12): e0145120 DOI: 10.1371/journal.pone.0145120

14 Vigan-Womas I, Guillotte M, Juillerat A, Hessel A, Raynal B, England P, Cohen JH, Bertrand O, Peyrard T, Bentley GA, LewitBentley A, Mercereau-Puijalon O. Structural basis for the ABO blood-group dependence of Plasmodium falciparum rosetting. PLoS Pathog 2012; 8(7): e1002781 DOI: 10.1371/journal.ppat.1002781

15 Rowe JA, Handel IG, Thera MA, Deans AM, Lyke KE, Kone A, Diallo DA, Raza A, Kai O, Marsh K, Plowe CV, Doumbo OK, Moulds JM. Blood group $\mathrm{O}$ protects against severe Plasmodium falciparum malaria through the mechanism of reduced rosetting. Proc Natl Acad Sci USA 2007; 104(44): 17471-17476 DOI: $\underline{10.1073 / \text { pnas.0705390104 }}$
16 Rask TS, Hansen DA, Theander TG, Gorm Pedersen A, Lavstsen T. Plasmodium falciparum erythrocyte membrane protein 1 diversity in seven genomes--divide and conquer. PLoS Comput Biol 2010; 6(9) DOI: 10.1371/journal.pcbi.1000933

17 Tekeste Z, Petros B. The ABO blood group and Plasmodium falciparum malaria in Awash, Metehara and Ziway areas, Ethiopia. Malar $\boldsymbol{J}$ 2010; 9: 280 DOI: 10.1186/1475-2875-9-280

18 Cholera R, Brittain NJ, Gillrie MR, LoperaMesa TM, Diakite SA, Arie T, Krause MA, Guindo A, Tubman A, Fujioka H, Diallo DA, Doumbo OK, Ho M, Wellems TE, Fairhurst RM. Impaired cytoadherence of Plasmodium falciparum-infected erythrocytes containing sickle hemoglobin. Proc Natl Acad Sci USA 2008; 105(3): 991-996 DOI: 10.1073/pnas.0711401105

19 LaMonte G, Philip N, Reardon J, Lacsina JR, Majoros W, Chapman L, Thornburg CD, Telen MJ, Ohler U, Nicchitta CV, Haystead T, Chi JT. Translocation of sickle cell erythrocyte microRNAs into Plasmodium falciparum inhibits parasite translation and contributes to malaria resistance. Cell Host Microbe 2012; 12(2): 187-199 DOI: 10.1016/j.chom.2012.06.007

20 Williams, T.N. How do hemoglobins S and C result in malaria protection? Journal of Infectious Diseases, 2011, 204, 1651-1653. https://doi.org/10.1093/infdis/jir640.

21 Okocha EC, Ibeh CC, Ele PU, Ibeh NC. The prevalence of malaria parasitaemia in blood donors in a Nigerian teaching hospital. $\boldsymbol{J}$ Vector Borne Dis 2005; 42(1): 21-24 [PMID: 15999457]

22 Moise, M.; Robert, H. Occurrence of Plasmodium falciparum malaria associated with ABO Blood Group in Darazo, Bauchi state, Nigeria, Electronic Journal of Biology, 2017, 13(3), 260-264.

23 Alemu G, Mama M. Assessing ABO/Rh Blood Group Frequency and Association with Asymptomatic Malaria among Blood Donors Attending Arba Minch Blood Bank, South Ethiopia. Malar Res Treat 2016; 2016: 8043768 [PMID: 26925291 PMCID: PMC4748098 DOI: 10.1155/2016/8043768] 
24 Tidi, S.; Amos, J.; Firyanda, E. Association between Plasmodium infection, Haemoglobin genotypes and Blood groups among Underfive nomadic Fulani of Northeastern Nigeria, International Journal of Malaria Research and Reviews, 2013, 1(2), 7-11.

25 Zerihun T, Degarege A, Erko B. Association of ABO blood group and Plasmodium falciparum malaria in Dore Bafeno Area, Southern Ethiopia. Asian Pac J Trop Biomed 2011; 1(4): 289-294 DOI: $10.1016 / \mathrm{S} 2221-1691(11) 60045-$ $\underline{2}$

26 Tadesse H, Tadesse K. Assessing the association of severe malaria infection and ABO blood groups in northwestern Ethiopia. $\boldsymbol{J}$ Vector Borne Dis 2013; 50(4): 292-296 [PMID: 24499852]

27 Uneke CJ, Ogbu O, Nwojiji V. Potential risk of induced malaria by blood transfusion in South-eastern Nigeria. Mcgill J Med 2006; 9(1): 8-13 [PMID: 19529802 PMCID: PMC2687905]

28 Cserti CM, Dzik WH. The ABO blood group system and Plasmodium falciparum malaria. Blood 2007; 110(7): 2250-2258 DOI: 10.1182/blood-2007-03-077602

29 Garg P, Upadhyay S, Chufal SS, Hasan Y, Tayal I. Prevalance of ABO and Rhesus Blood Groups in Blood Donors: A Study from a Tertiary Care Teaching Hospital of Kumaon Region of Uttarakhand. J Clin Diagn Res 2014; 8(12): $\quad$ FC16-19 DOI: 10.7860/JCDR/2014/9794.5355

30 Jeremiah ZA. Abnormal haemoglobin variants, $\mathrm{ABO}$ and $\mathrm{Rh}$ blood groups among student of African descent in Port Harcourt, Nigeria. $\boldsymbol{A} \boldsymbol{f r}$ Health Sci 2006; 6(3): 177-181 DOI: 10.5555/afhs.2006.6.3.177

31 Otajevwo,F. D . Prevalence of malaria parasitaemia and its association with $\mathrm{ABO}$ blood grouping among students of Igbinedion University Okada, Nigeria, British Journal of Medicine and Medical Research, 2013, 3, 1164-1177. DOI: $10.9734 / \mathrm{BJMMR} / 2013 / 1745$

32 Omotosho, I. A Survey of ABO, Rhesus (D) Antigen and Haemoglobin Genes Variants in Oyo State, Nigeria, Nigerian Journal of Physiological Sciences, 2015, 30, 125-129.
33 Buseri, F.N.; Okonkwo, C.N. Abnormal hemoglobin genotypes and $\mathrm{ABO}$ and rhesus blood group associated with HIV-infection among HIV-exposed infants in North Western Nigeria, Pathology and Laboratory Medicine $\begin{array}{llll}\text { International, } \quad 2014, & 6, & 15-20 .\end{array}$ https://doi.org/10.2147/PLMI.S61046.

34 Ebadan, M.I.; Obodo, B.N.; Amiegheme, F.E.; Uwaifo, F.; Omigie, B.E.; Iyevhobu, L.K.; Umassor, A.C.; Aiyeki, G.E. Prevalence and susceptibility of malaria parasites infection in association with blood group and haemoglobin genotype polymorphism in pregnancy, International Journal of Community Research, 2017, 6(2), 2-8.

35 Akhigbe, R.E; Ige, S.F; Afolabi, A.O; Azeez, O.M; Adegulola, G.L.; Bamidele, J.O. Prevalence of haemoglobin variant, $\mathrm{ABO}$ and Rhesus blood group in Lodoke Akintola University of Technology, Ogbomosho, Nigeria, Trends in Medical Research, 2009, 4, 24-29. DOI: $10.3923 / \mathrm{tmr} .2009 .24 .29$

36 Bassey, S.E.; Izah, S.C. Some determinant factors of Malaria Prevalence in Nigeria, Journal of Mosquito Research, 2017, 7(7), 48-58. DOI: $10.5376 / \mathrm{jmr} .2017 .07 .0007$

37 Esan, A. Assessment of Haemoglobin Variants in Malaria Infected Individuals Using Haematological Parameters, International Journal of Hematological Disorders, 2015, 2(1), 4-9. DOI: $\underline{10.12691 / \mathrm{ijh} \text {-2-1-2. }}$

38 Ademolue TW, Amodu OK, Awandare GA. Sickle cell trait is associated with controlled levels of haem and mild proinflammatory response during acute malaria infection. Clin Exp Immunol 2017; 188(2): 283-292 [PMID: 28142190 PMCID: PMC5383446 DOI: 10.1111/cei.12936]

39 Otajevwo, F.;Igoniwari,S.Malaria Parasitaemia Association with ABO Blood Types among Students of a Private University in Western Delta, Nigeria, International Journal of Tropical Disease \& Health, 2014, 4(5), 540554. 